مقايسه تغييرات شاخص تنش آبى گياه لوبياجيتى در شرايط آبيارى سطحى و تيب با استفاده از دماسنج مادون قرمز

على حيدر نصر الهى"، حامد احمدى، ياسر سبزوارى و سميه نورى'

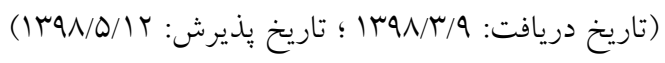

جكيده

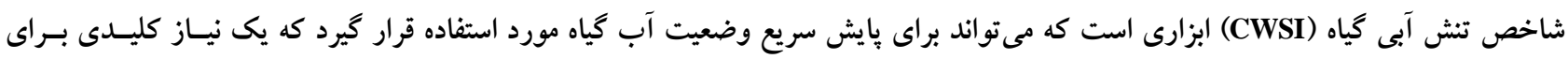

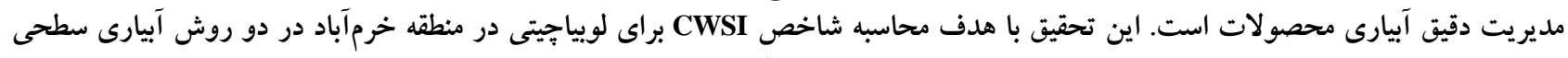

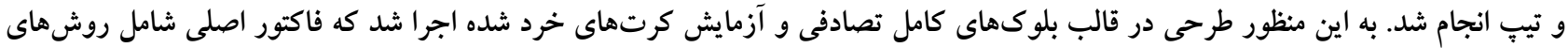

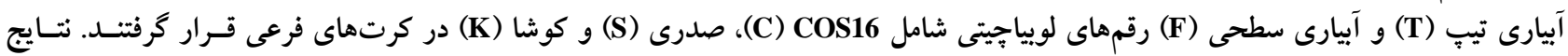

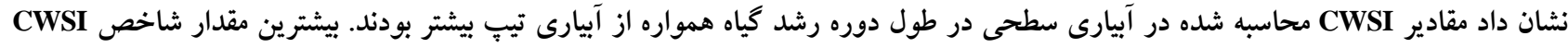

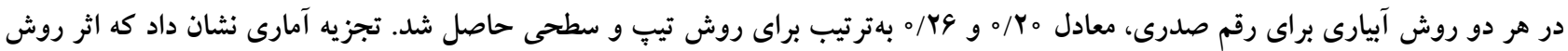

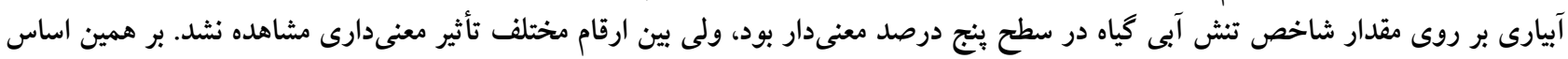

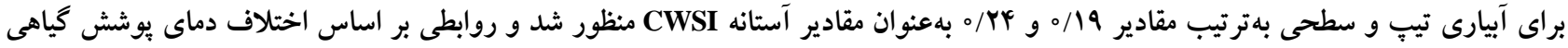

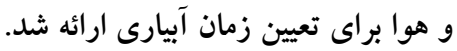

وازمهاى كليدى: برنامهريزى آبيارى، تنش آبى، دماى برى 
نشان داد اختلاف دماى بوشش سبز گياهى و هوا بهتنهايى براى

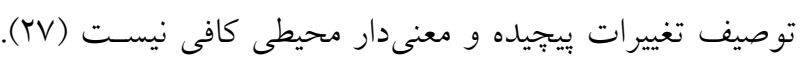

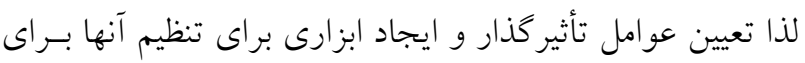

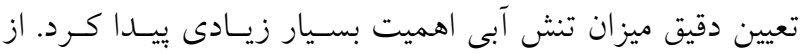

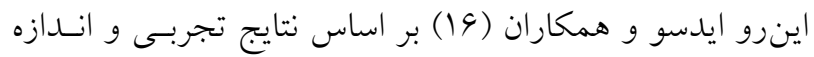

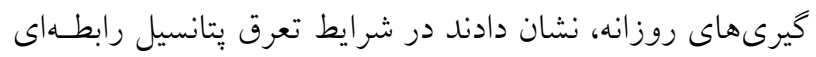

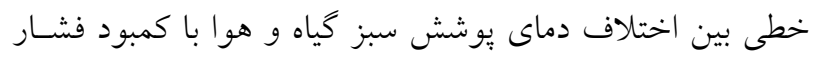

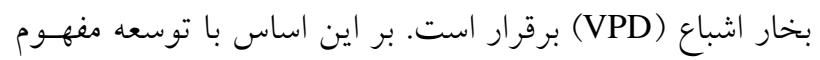

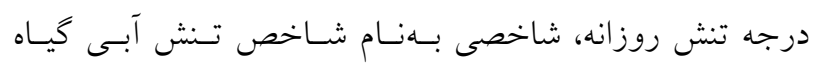
CWSI را معرفى كردند. (Crop Water Stress Index :CWSI)

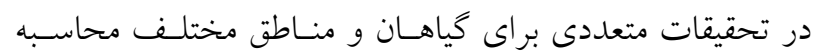
شده و بهعنوان شاخصى مناسب بـراى تعيسين تـنش آبسى كيـاه

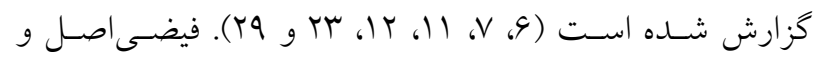
همكاران (9)، بيان كردند اخر جهه در محاسبه شاخص CWSI از لز مقادير رطوبت خاك و كياه استفاده نمىشود و تنها بازتابهـاى

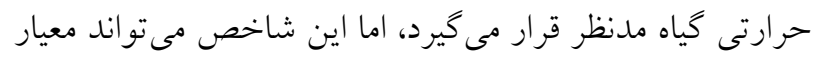

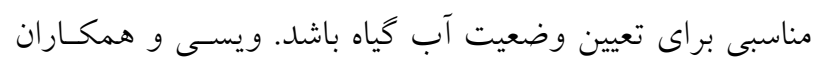
(YN)

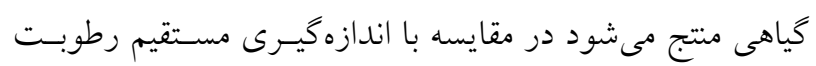

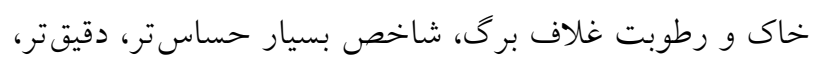

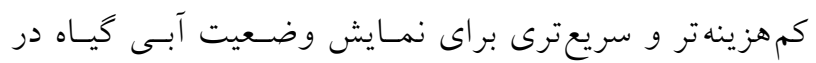

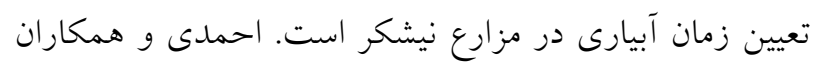

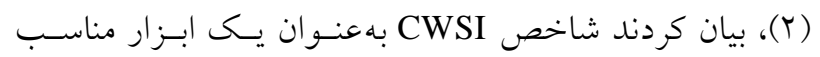

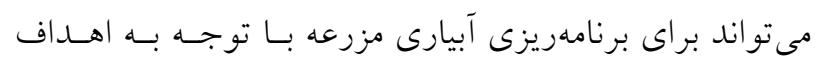

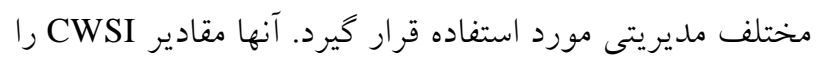

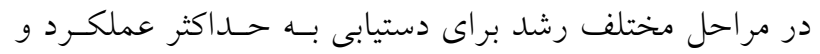

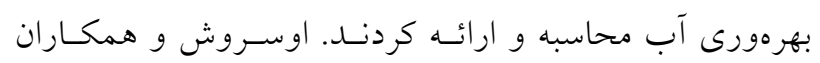

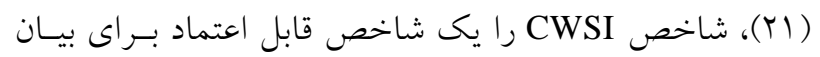

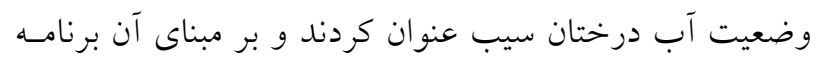

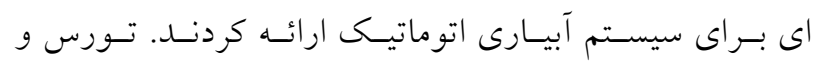

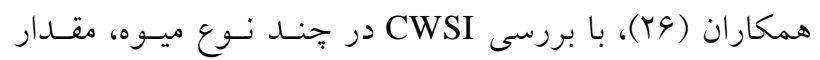

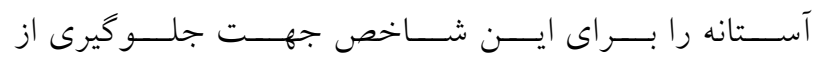

طراحسى برنامـهـ دقيـق آبيـارى از الزامـات مـــيريت آبيـارى

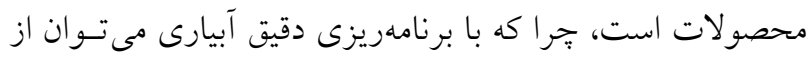

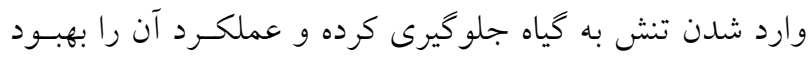
بخشيد. در بين متغيرهاى محيطى، تنش آبى را مى توان مهم ترين

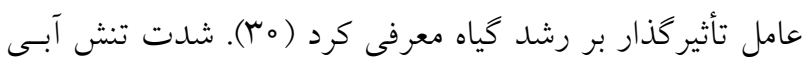

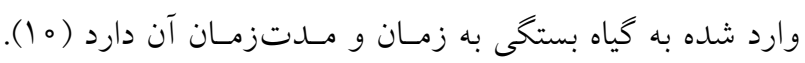

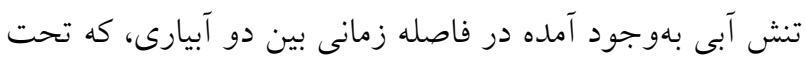

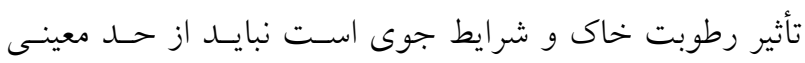

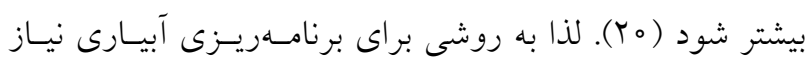

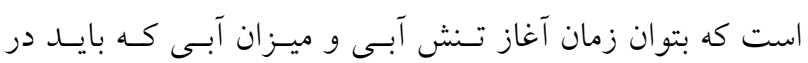

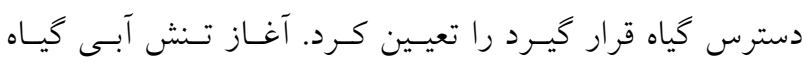

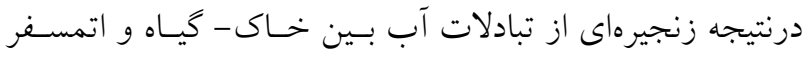

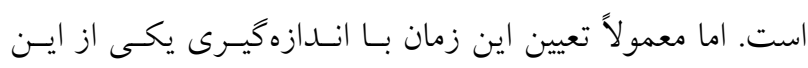

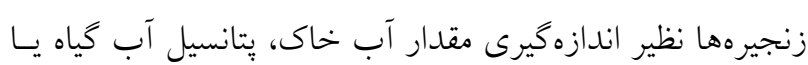

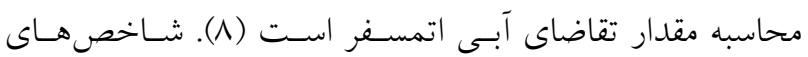

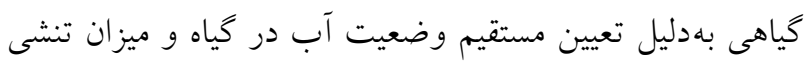
كه تحت تأثير رطوبت خاى و اتمسفر ايجاد مىشـود در روش

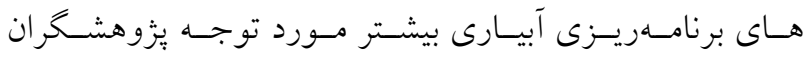

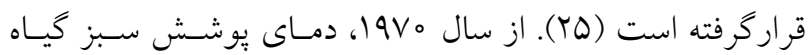
بهعنوان يك شاخص كياهى براى تعيين تنش آبى معرفى شــد،

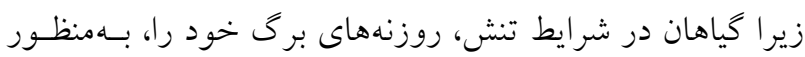

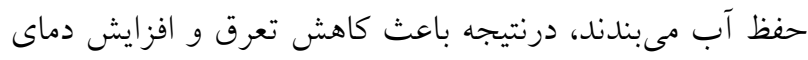
سطح برى خود مىشوند. از اين رو تحقيقـاتى در جهـت بـت ارائسه.

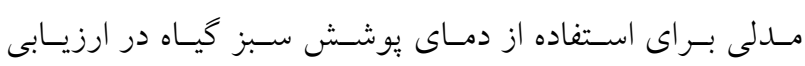

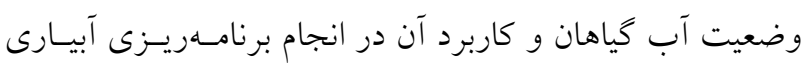

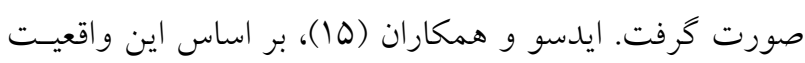
كه دماى يوشش سبز گياه در شر ايط حداكثر تعرق، برابر يا كمتر

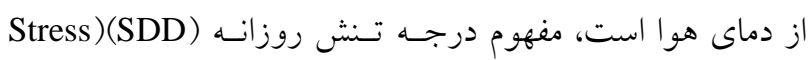

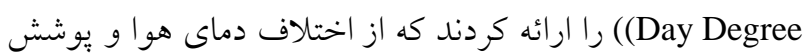
سبز در زمان حداكثر تنش روزانـه (حسدود يـك سـاعت و نسيم بعدازظهر خورشيدى) محاسبه مىشـد. در ايسنحسال تحقيقـات 
جدول ا. ميانگين ماهانه بارامترهاى هواشناسى منطقه در طول دوره رشد

\begin{tabular}{|c|c|c|c|c|}
\hline شهريور & 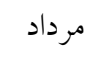 & تير & 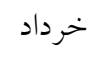 & يَارامتر هواشناسى \\
\hline$r N / r)$ & $Y / N Q$ & $41 / 10$ & Tr/Ar & بيشينه درجه حرارت (سانتى گراد) \\
\hline $1 V / 9 \circ$ & $r \circ / \Lambda$ & $r 0 / 90$ & $10 / \pi r$ & كمينه درجه حرارت (سانتى گراد) \\
\hline$r_{0 / 9 \Lambda}$ & $r V / 09$ & $r N / \circ 9$ & 99190 & بيشينه رطوبت نسبى (درصد) \\
\hline$V / 90$ & V/Tr & $\mathrm{V} / \mathrm{VV}$ & IN/NY & كمينه رطوبت نسبى (درصد) \\
\hline$V / 4 Q$ & $9 / 0 r$ & $9 / 91$ & $V / 9 \Lambda$ & سرعت باد (متر بر ثانيه) \\
\hline$r \circ \varphi / 0$ & $M \mu 1 / r$ & $r \wedge \mu / r$ & $r g r / 9$ & ميزان تبخير (ميلى متر) \\
\hline
\end{tabular}

\section{مواد و روشها - - ماد}

اين تحقيق از خردادماه لغايت شهريورماه سال IraV بـه مــدت جهار ماه در مزرعه تحقيقاتى دانشكده كشاورزى و منابع طبيعى

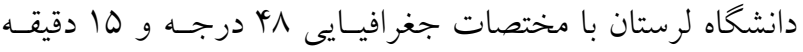

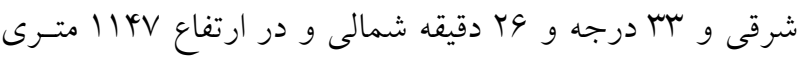
از سطح دريا انجام شد. بارامترهاى هواشناسى منطقهـ در طـول

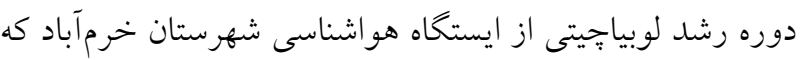

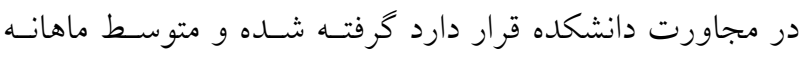

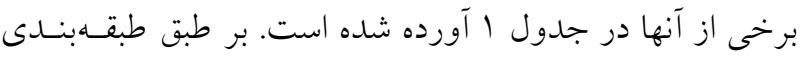

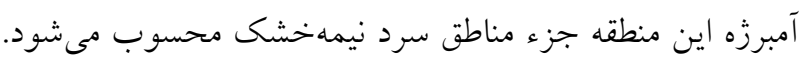

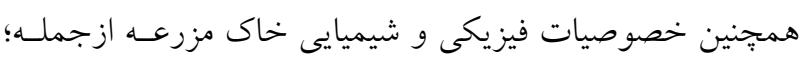

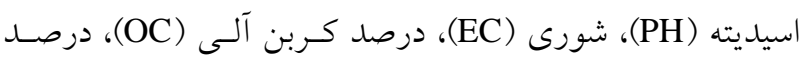

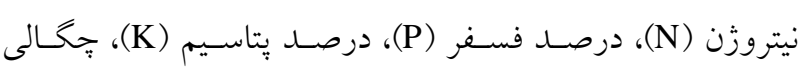

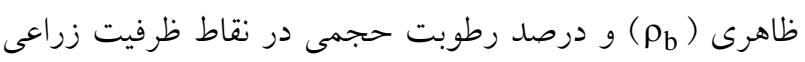

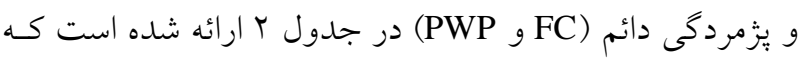

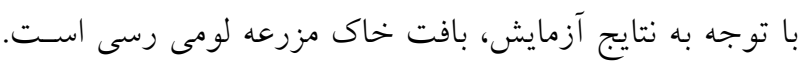

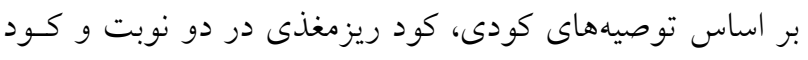
نيترات در يك نوبت به روش دستى در اختيار گياه قرار گرفت دون.

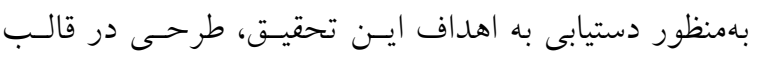

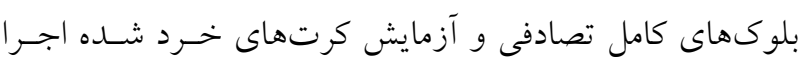

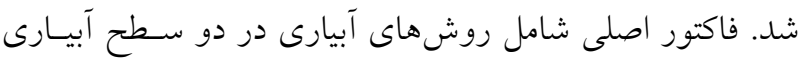
تيب (T) و آبيارى سطحى (F) در كـرتهـاى اصـلى و فـاكتور فرعى شامل رقمهاى لوبياجيتى شامل COS16 (C)، صدرى (S)

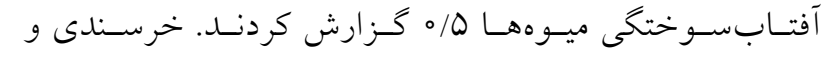

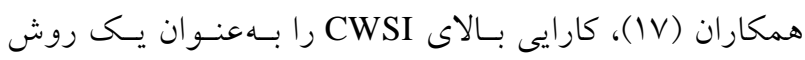

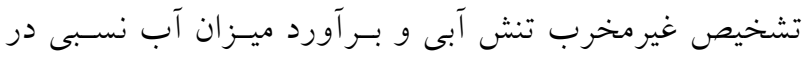

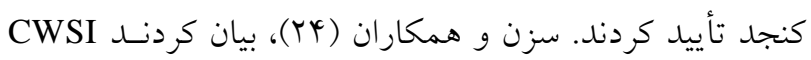

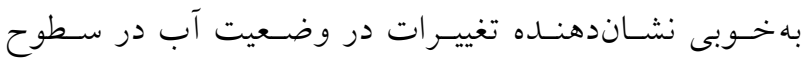

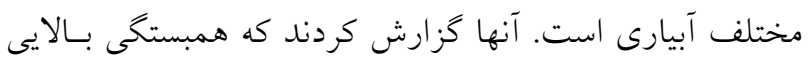

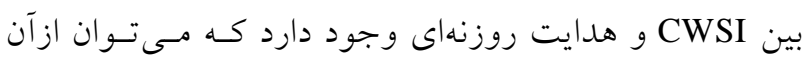

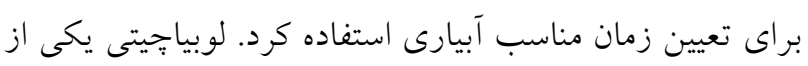

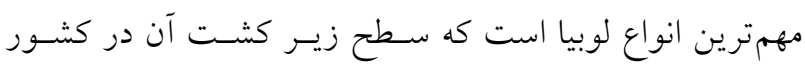

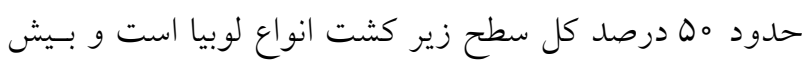

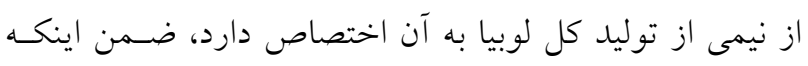

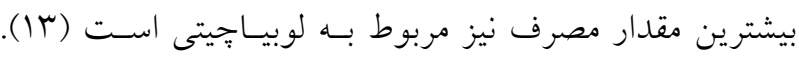

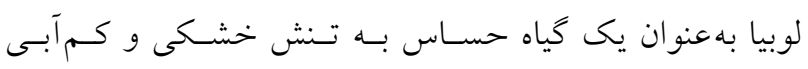

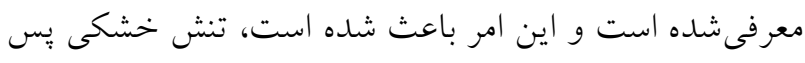

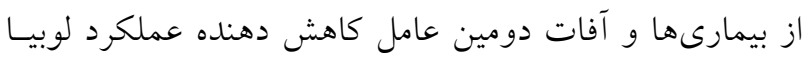

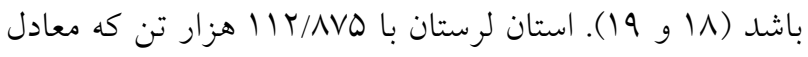

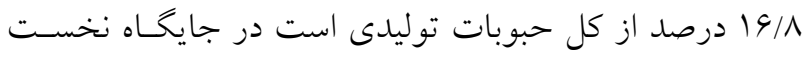

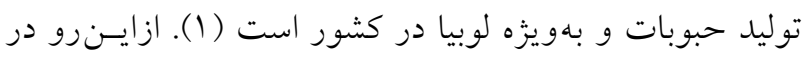

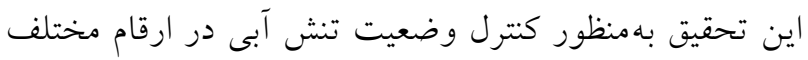
كياه لوبياجيتى تحت دو روش آبيارى جوى و يشتهاى و تيّ، دماى يوشش كياهى در طول دوره رشد با استفاده از دماسـنج

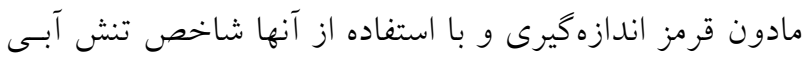
كياه (CWSI) - (C) مقايسه شد. 
جدول r. خصوصيات فيزيكى و شيميايى خاك مزرعه

\begin{tabular}{|c|c|c|c|c|c|c|c|c|c|c|}
\hline $\begin{array}{c}\text { PWP } \\
\text { (درصد حجمى) }\end{array}$ & $\begin{array}{c}\text { FC } \\
\text { (درصد حجمى) }\end{array}$ & $\begin{array}{c}\rho b \\
(\mathrm{gr} / \mathrm{cm} 3)\end{array}$ & $\begin{array}{c}\mathrm{K} \% \\
(\mathrm{ppm})\end{array}$ & $\begin{array}{c}\mathrm{P} \% \\
(\mathrm{ppm})\end{array}$ & $\begin{array}{c}\mathrm{N} \% \\
(\mathrm{ppm})\end{array}$ & $\begin{array}{l}\text { OC } \\
\%\end{array}$ & $\begin{array}{c}\mathrm{EC} \\
(\mathrm{dS} / \mathrm{m})\end{array}$ & $\mathrm{pH}$ & بافت خاى & غمق \\
\hline $14 / 0$ & $r Q / \varphi$ & $1 / 1 T$ & $\Delta Y / D$ & YY & $0 / 09$ & $\circ / 9 V$ &.$/ 90$ & V/OT & لوم- رسى & 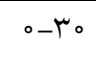 \\
\hline $\mid \psi / 4$ & TY/० & $1 / 1 r$ & $r 9 / 0$ & r & $\circ / \circ \wedge$ & $\circ / \mathrm{V} \Lambda$ & $0 / 94$ & $\mathrm{~V} / \mathrm{VI}$ & لوم- رسى & $\mu_{0-9 \circ}$ \\
\hline
\end{tabular}

جدول r. خصوصيات كيفى آب آبيارى در طول فصل

\begin{tabular}{ccccccc}
\hline $\mathrm{SAR}$ & $\mathrm{Na}^{+}(\mathrm{meq} / \mathrm{l})$ & $\mathrm{Mg}^{2+}(\mathrm{meq} / \mathrm{l})$ & $\mathrm{Ca}^{2+}(\mathrm{meq} / \mathrm{l})$ & $\mathrm{TDS}(\mathrm{meq} / \mathrm{l})$ & $\mathrm{EC}(\mathrm{ds} / \mathrm{m})$ & $\mathrm{pH}$ \\
\hline$\circ / \mathrm{r}$ & $1 / \mathrm{N}$ & $1 / 9$ & $\mathrm{r} / 9$ & $\mathrm{rqV}$ & $\circ / 9$ & $\mathrm{~V}$ \\
\hline
\end{tabular}

$\mathrm{ET}_{\mathrm{C}}=\mathrm{K}_{\mathrm{C}} \times \mathrm{ET}_{0}$

در اين رابطـه: ETC: تبخيـر و تعـرق گيـاه لوبيـاجيتى و و ضريب كياهى لوبياجيتى است. بر اسـاس دور آبيـارى سـهروزه براى روش تيب و هفتروزه روش سطحى و رانــدمان آبيـارى ه9 درصد، مقدار آب مورد نياز محاسبه و در اختيار گيساه قـرار مى گرفت. آب مورد استفاده از طريق جّاه موجـود در دانشـكده

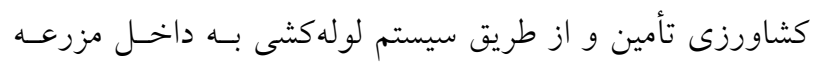

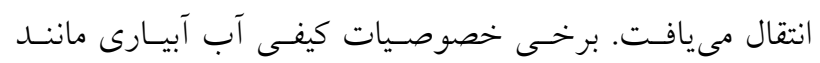
اسـيديته (PH)، شـورى (EC)، مجمــوع مـواد جامـــ محلــول

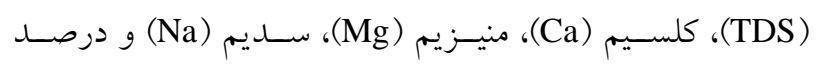

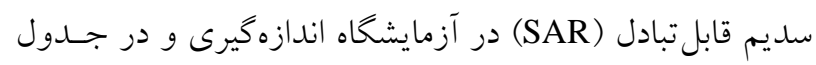
ب آمده است. در روش تيب آب مورد نياز بـراى آبيـارى در دو

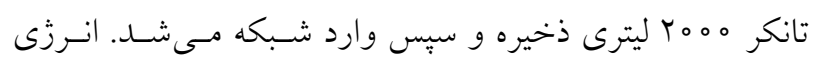

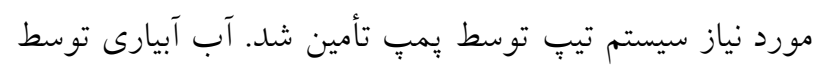
فيلتر تورى تصفيه و حجم آن توسط كنتسور حجمسى كتتـرل و فشار آن نيز با استفاده از فشارسنج و شير كنتـرل فشـار، تنظيم شده و يس از عبور از لولـههـاى •ها و بس ميلـىمتـرى توسط

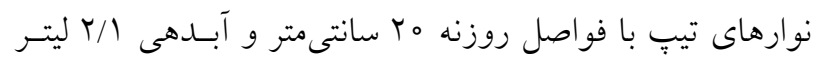
در ساعت در اختيار گياه قرار مى گرفت. در طول دوره رشـــ در

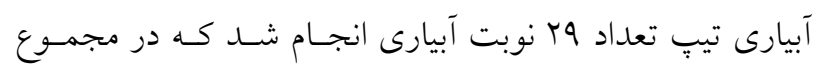

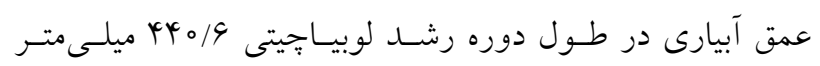
بهدست آمل. در آبيارى سطحى نيز حجم آب مورد نيـاز توسط
و كوشـا (K) بودنـــ كـهـ در كـرتهــاى فرعى قـرار كرفتــد. تيمارهاى تحقيق شامل: روش آبيـارى تيـٍ و رقــم لوبيـاجيتى COS16) TC

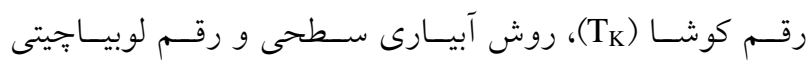

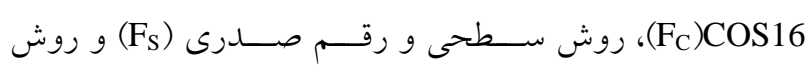
سطحى و قم كوشا (FK) است. هر كدام از كرتهـاى آزمايشى

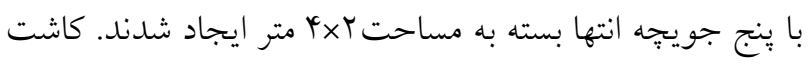

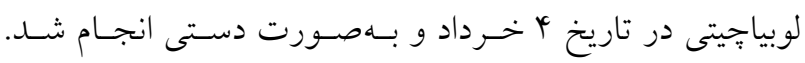

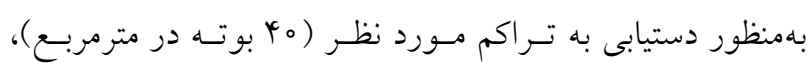

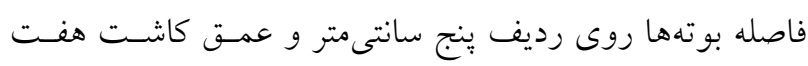

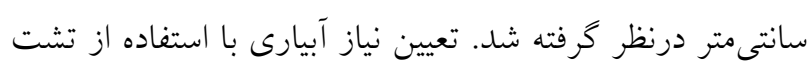
تبخير كلاس A تعبيه شده در مزرعه انجام شد. بـر اسـاس ايسن روش ابتدا تبخير و تعرق گياه مرجع با استفاده از مقادير تبخيـر از تشت و با استفاده از رابطه زير محاسبه شد:

$\mathrm{ET}_{0}=\mathrm{K}_{\mathrm{p}} \times \mathrm{E}_{\mathrm{p}}$

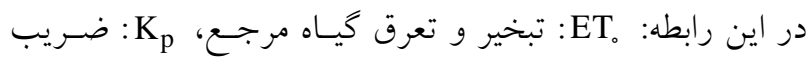
تشت تبخير و Ep ميزان تبخير از تشـت تبخيـر اسـت. مقـدار ضريب تشت تبخير \/ه درنظر گرفته شد. سيس بــا اسـتفاده از ضرايب گياهى ارائه شده براى لوبيا توسط فائو، كه براى مراحل

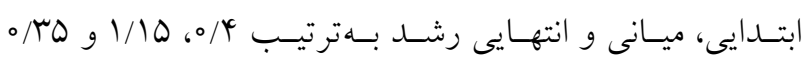
برآورد شده تبخير و تعرق كياه لوبياجيتى از طريـق رابطـه زيـر محاسبه شد: 
آمده براى اختلاف دماى يوشش سبز گياه و هوا در برابر كمبود فشار بخار هوا تعيين شد (رابطه ه):

$\mathrm{VPD}=\left(0.6108 * \operatorname{EXP}\left(\frac{17.27 * \mathrm{~T}_{\mathrm{a}}}{\mathrm{T}_{\mathrm{a}}+237.3}\right) \times\left(1-\frac{\mathrm{RH}}{100}\right)\right.$

$\left(\mathrm{T}_{\mathrm{c}}-\mathrm{T}_{\mathrm{a}}\right)_{1 . \mathrm{l}}=\mathrm{a}-\mathrm{b}(\mathrm{VPD})$

در روابط فوق؛ VPD: كمبود فشار بخار اشباع (ميلى بار)، Ta

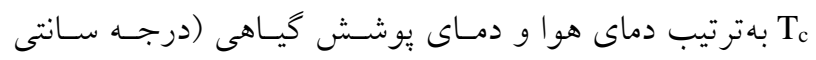

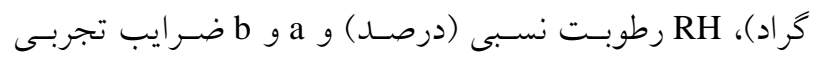

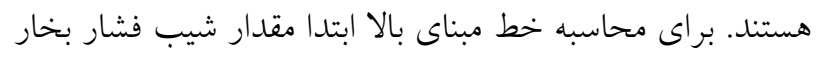

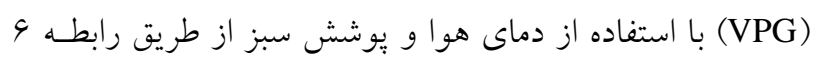

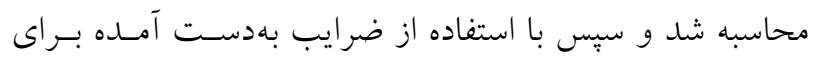

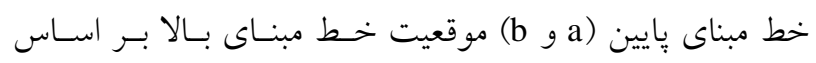
رابطه V تعيين شد:

$$
V P G=e_{s}\left(T_{c}\right)-e_{s}\left(T_{a}\right)
$$

$$
\left(\mathrm{T}_{\mathrm{c}}-\mathrm{T}_{\mathrm{a}}\right)_{\mathrm{u} . \mathrm{l}}=\mathrm{a}+\mathrm{b} \cdot|\mathrm{VPG}|
$$

براى محاسبه CWSI، دماى يوشش سبز در روزهاى قبل آبيارى

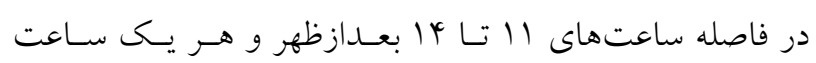

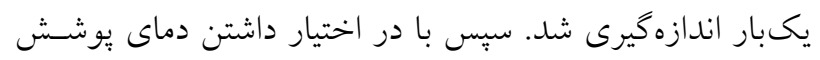

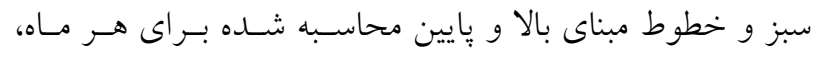
CWSI بهروش ايدسو طبق رابطه $\wedge$ محاسبه شد (19):

$$
\text { CWSI }=\frac{\left(T_{c}-T_{a}\right)_{m}-\left(T_{c}-T_{a}\right)_{l l}}{\left(T_{c}-T_{a}\right)_{u l}-\left(T_{c}-T_{a}\right)_{l l}}
$$

\section{نتايج و بحث}

\section{محاسبه خطوط مبناى بايين و بالا}

با توجه به معادلههاى ارائه شده در بخش قبل وبل و و دائه دادهاى مزرعه

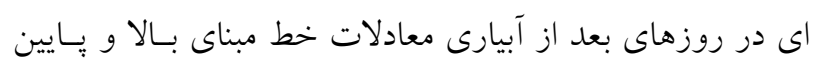
محاسبه شد. بهعلت بالا بودن تعداد دادههاى مزرعهاى، بهعنوان

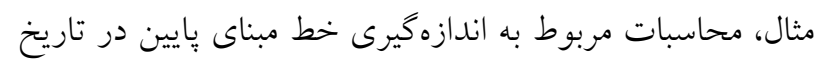

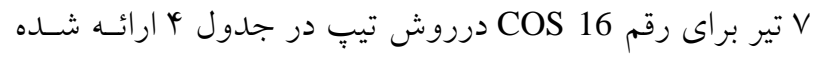

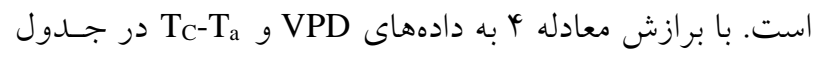

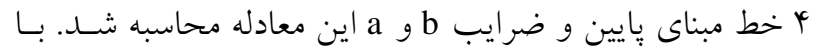
b

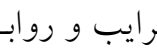
ضن

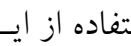

لوله انتقال و توسط كنتور حجمى در اختيار گياه قرار گرفت. در

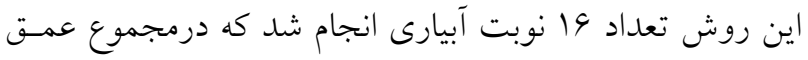

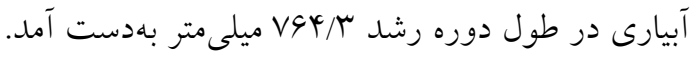

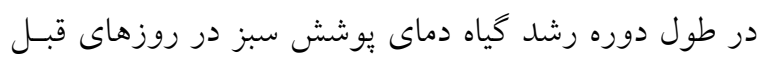

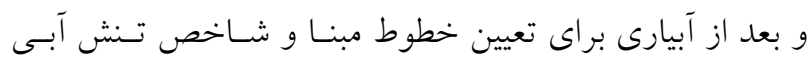
كياه توسط دماسنج مادون قرمز اندازهگيرى شد. دماسنج مـادون قرمز دستكاهى است كه تشعشعات مادون قرمز خـارج شـــه از

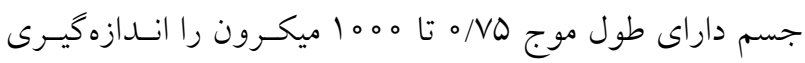

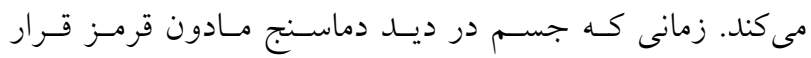

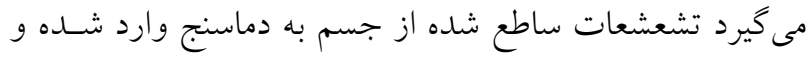

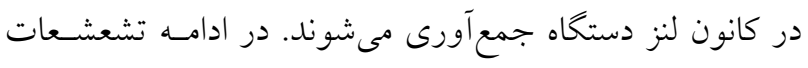
جمع آورى شده به يـك سـيخنال الكتريكسى تبــيل شــده و بـر

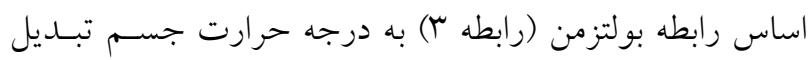

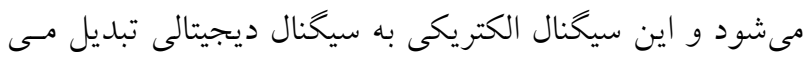
شود كه روى خروجى دستخاه نمايش داده مى شود: $\mathrm{W}=\mathrm{rT}_{\mathrm{S}}^{4}$

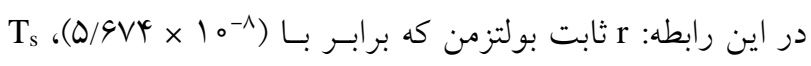

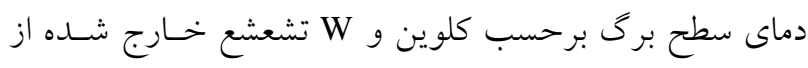

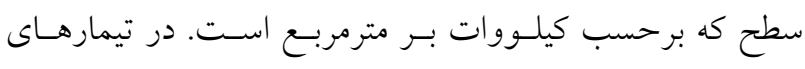

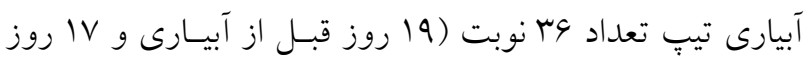

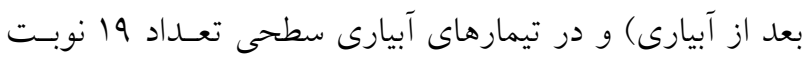

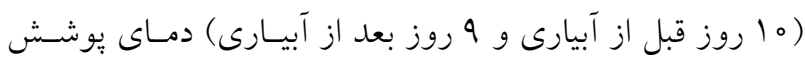

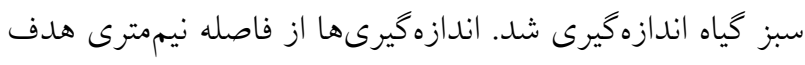

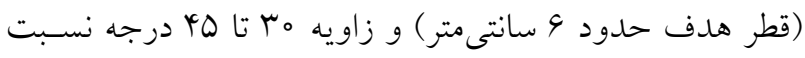

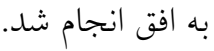

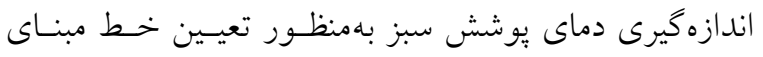

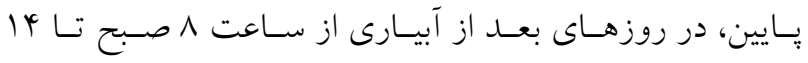

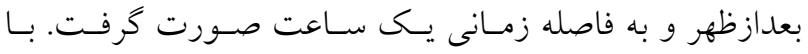

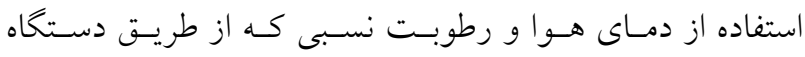

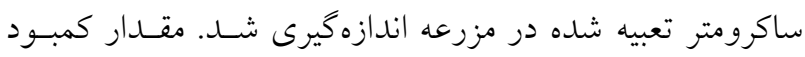

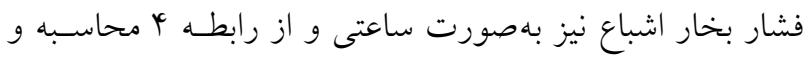

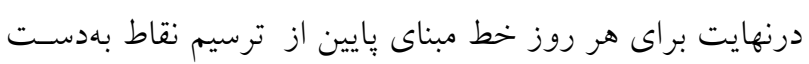


جدول \&. اندازهگيرى و محاسبات خط مبناى بايين رقم COS 16 در V تير در روش تيب

\begin{tabular}{|c|c|c|c|c|c|c|c|}
\hline 14 & $1 \pi$ & Ir & 11 & 10 & 9 & $\Lambda$ & ساعت اندازهيرى \\
\hline Tr/A & 狊 & 栏/9 & $T / \Lambda$ & Ml/ & r。/。 & $r V / r$ & Tc $\left({ }^{\circ} \mathrm{C}\right)$ \\
\hline$\varphi_{0} / 0$ & $41 / 1$ & $r \circ / V$ & $4 \circ / 1$ & re/A & $M Y / \Lambda$ & $T V / T$ & Ta $\left({ }^{\circ} \mathrm{C}\right)$ \\
\hline$-V / T_{0}$ & $-\Lambda / 10$ & $-V / 10$ & -V/R & $-Q / \circ \circ$ & $-\psi / \Lambda \circ$ & - & $(\mathrm{Tc}-\mathrm{Ta})\left({ }^{\circ} \mathrm{C}\right)$ \\
\hline $9 / 1$ & $\Lambda / \Delta$ & $9 / 0$ & $10 / 4$ & $19 / 1$ & $1 \mathrm{~V} / \mathrm{S}$ & $19 / 4$ & RH (\%) \\
\hline $99 / 01$ & $V 1 / 9 \circ$ & G9/rT & $99 / 49$ & $\Delta Y / M$ & $\varphi \Delta / \wedge \Delta$ & $r q / \circ q$ & VPD (mbar) \\
\hline
\end{tabular}

جدول ه. محاسبات مربوط به تعيين خط مبناى بالا رقم COS 16 در Vتير در روش تيب

\begin{tabular}{|c|c|c|c|c|c|c|c|}
\hline 14 & Ir & Ir & 11 & 10 & 9 & $\wedge$ & ساعت \\
\hline$\hat{y} \%$ & $4 \mid / 1$ & $\varphi \circ / v$ & $\varphi \circ / 1$ & re/A & $\mu y / \Lambda$ & $T V / T$ & Тa \\
\hline$\varphi / \circ \mu$ & $r / \circ \mu$ & $\varphi / \circ \mu$ & $\varphi / \circ r$ & $\varphi / \circ r$ & $r / 0 r$ & $r / 0 r$ & $\mathrm{a}$ \\
\hline.$/ \mathrm{V}$ & $0 / 1 \mathrm{~V}$ & $0 / I V$ &.$/ \mathrm{V}$ & $\circ / \mathrm{V}$ & $\circ / \mathrm{V}$ & $\circ / \mathrm{VV}$ & b \\
\hline$k y / 0 r$ & $\varphi Q / \wedge r$ & YQT/R & $k y / l r$ & $\varphi \circ / \Lambda \mu$ & MN/Ar & & Tc \\
\hline$V Y / 01$ & $V Q / Y \Lambda$ & $V V / a Y_{0}$ & $V T / Y_{0}$ & Go/Dr & $04 / 19$ & $r \Delta / \circ q$ & ea* \\
\hline $19 / 19$ & $9 V / 91$ & $9 Q / 41$ & $\Lambda 9 / 94$ & $V Q / Y q$ & $9 V / 91$ & $\mu \forall / \mu 1$ & ec* \\
\hline $1 V / 10$ & $\mid N / g r$ & $|\Lambda / Y|$ & IV/TY & IY/VG & $\mid r / 4 r$ & $Q / T r$ & VPG \\
\hline $9 / 90$ & $V / T \circ$ & $\mathrm{V} / \mathrm{Ir}$ & $9 / 99$ & $G / 0 Y$ & $9 / \mu 1$ & $0 / 9 \circ$ & (Tc-Ta) ul \\
\hline
\end{tabular}

فشار بخار هـوا در طسول دوره در محسدوده rY/0Y ميلسىبـار تـا

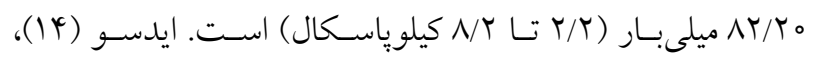

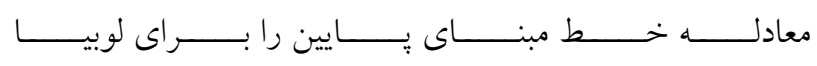
به بورت ارائه كرد. آسمان

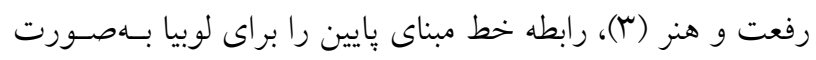
بهدست آوردند. $\left(\mathrm{T}_{c}-\mathrm{T}_{\mathrm{a}}\right)_{\mathrm{l} . \mathrm{l}}=1.18$-0.10VPD

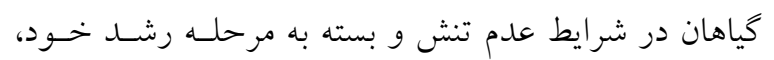

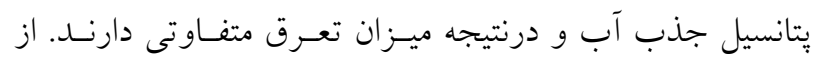

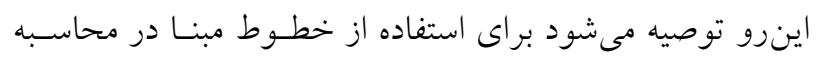
شاخص CWSI، اين خطوط مبنا براى هـر مــاه جداكانـه ارائسه

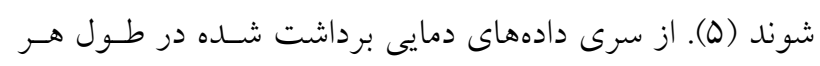

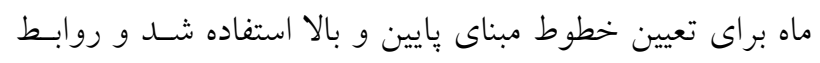

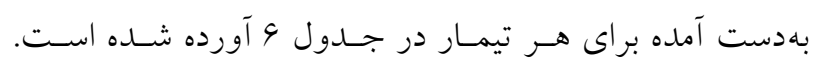

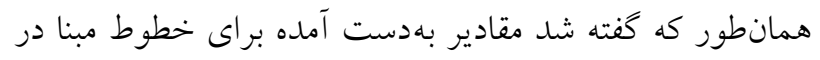

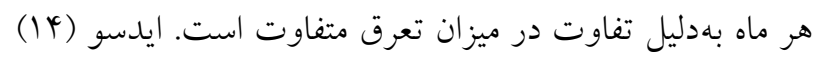

مورد نظر، محاسبات خط مبنـاى بـالا در جــدول ه ارائسه شـــ.

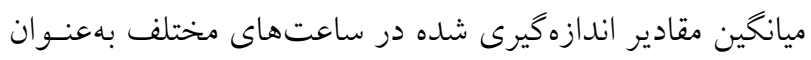
خط مبناى بالا درنظر كرفته شد.

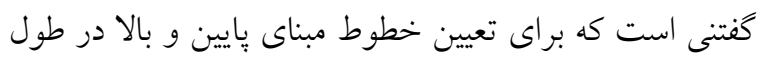

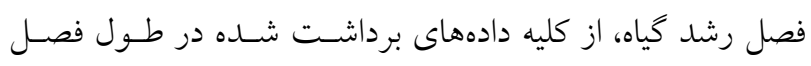

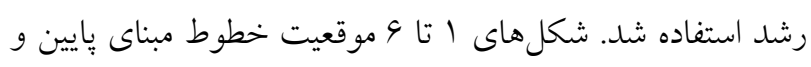

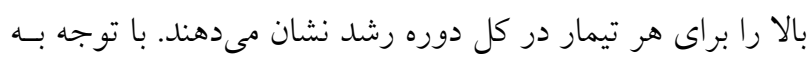

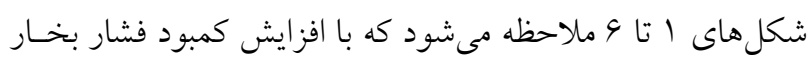

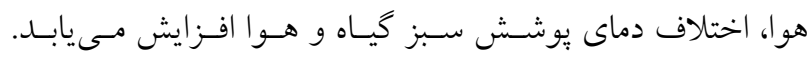

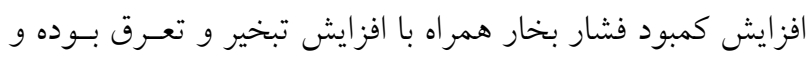

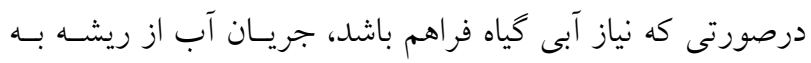

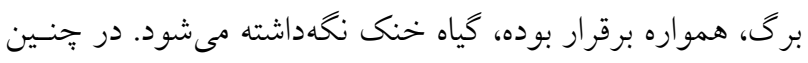

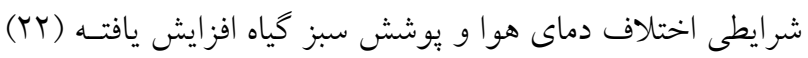
و دماى كياه نسبت به دماى هوا با شدت كمترى افزيش مىيابـــ در روابط بهدست آمده در اين شكل ها محــدوده تغييـرات كمبـود 


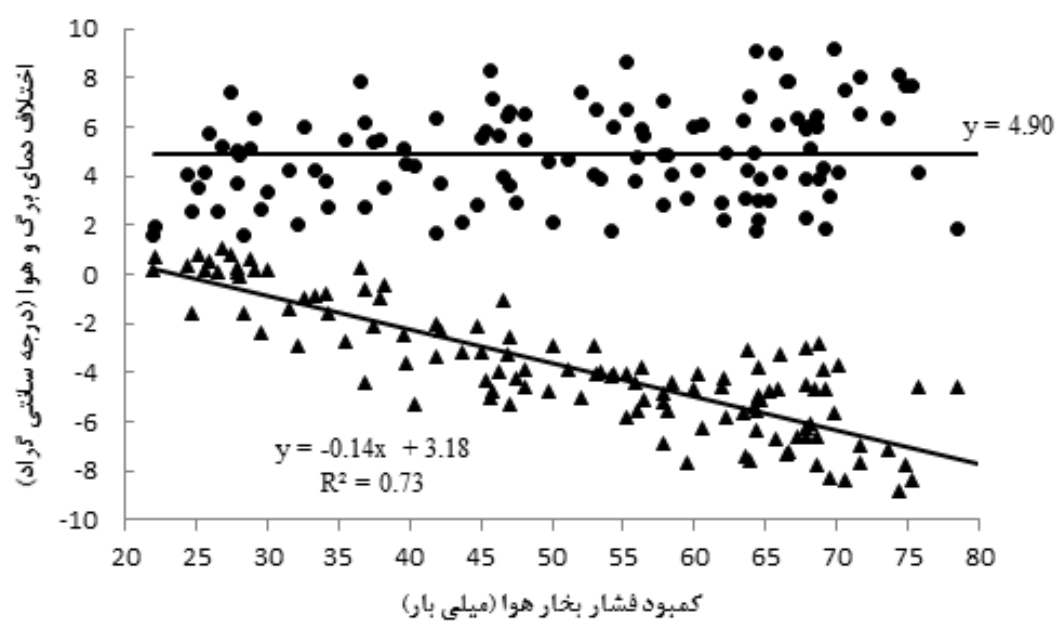

شكل 1. نمودار خط مبناى بايين و بالا در كل دوره رشد رقم COS 16 در روش تيب

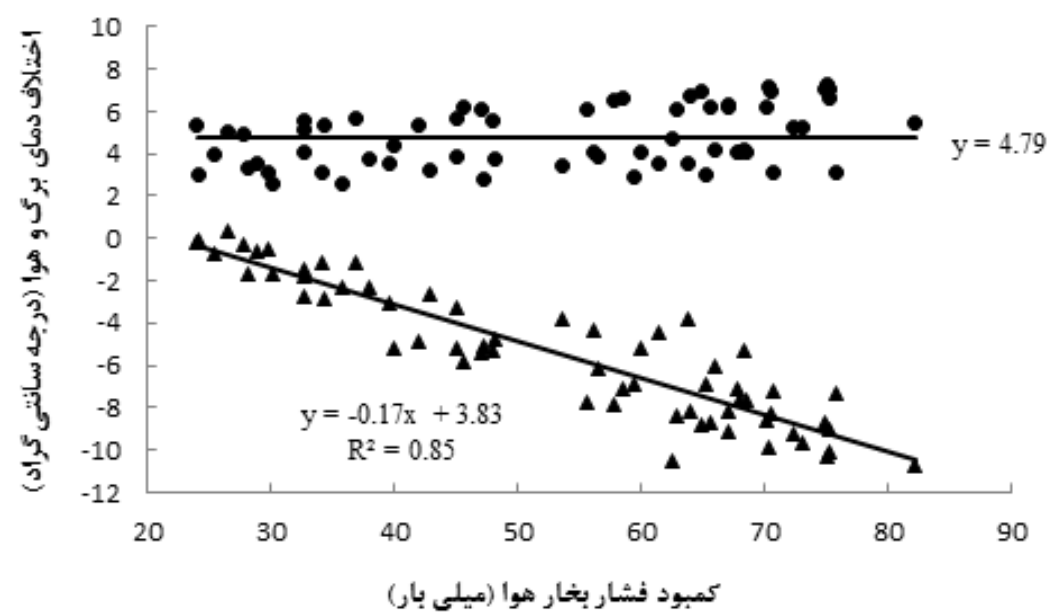

شكل r. نمودار خط مبناى بايين و بالا در كل دوره رشد رقم COS 16 در روش سطحى

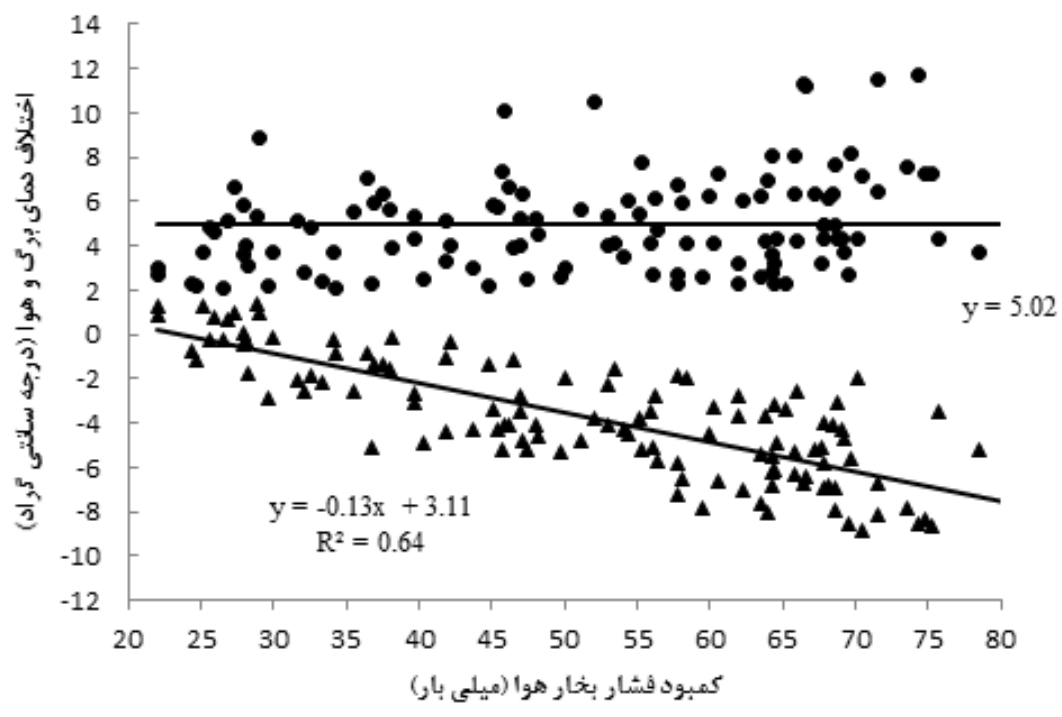

شكل r. نمودار خط مبناى بايين و بالا در كل دوره رشد رقم صدرى در روش تيب 


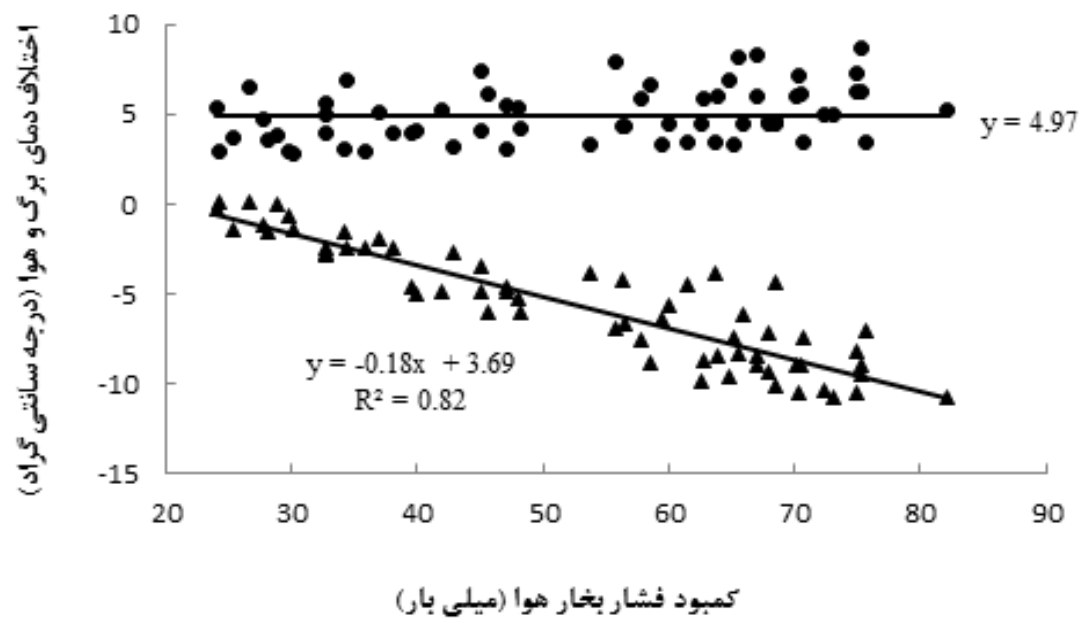

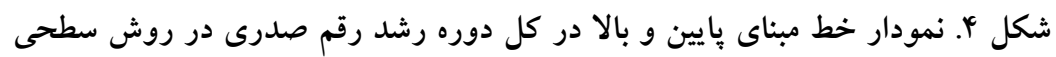

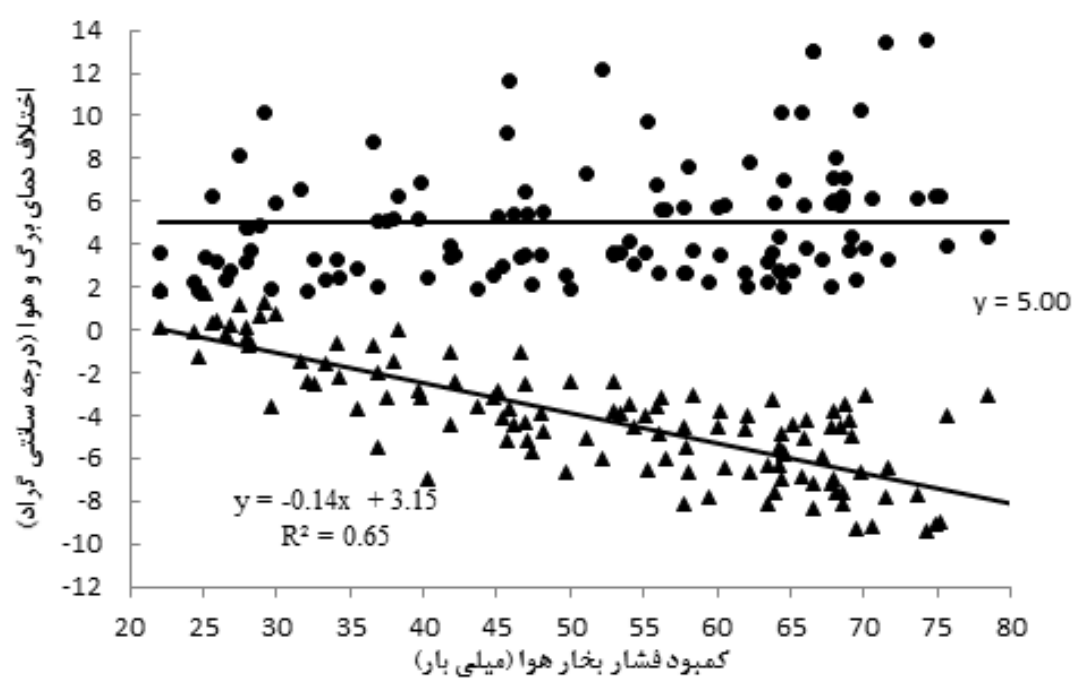

شكل ه. نمودار خط مبناى بايين و بالا در كل دوره رشد رقم كوشا در روش تيب

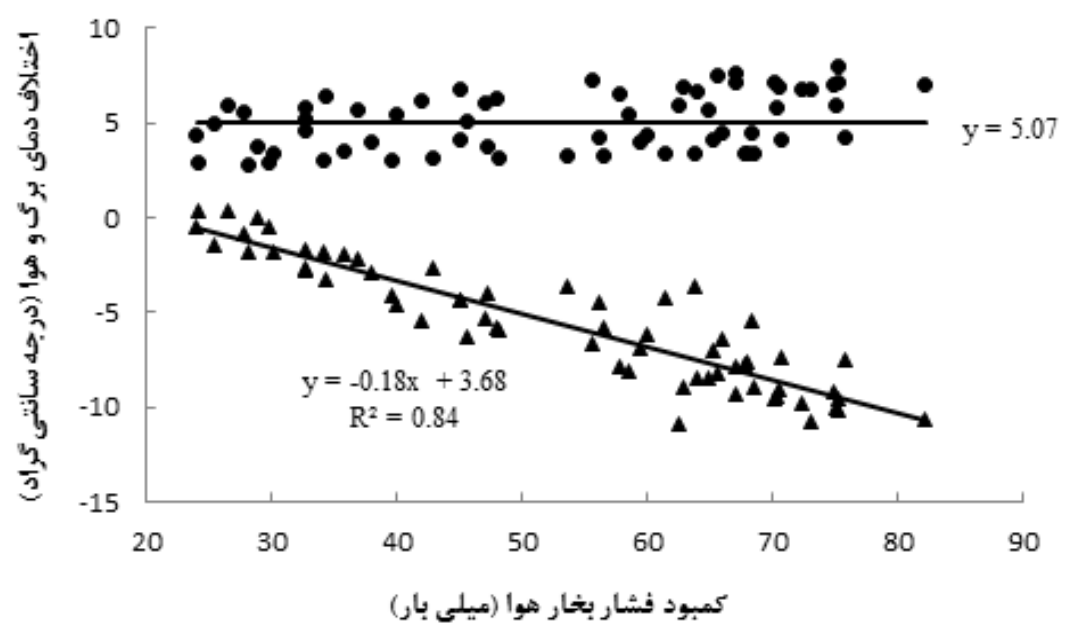

شكل 9. نمودار خط مبناى بايين و بالا در كل دوره رشد رقم كوشا در روش سطحى بـ 
جدول 9. روابط خط مبناى پايين و بالا در هر ماه براى تيمارهاى مختلف

\begin{tabular}{|c|c|c|c|c|}
\hline خط مبناى بالا & $\mathrm{R}^{2}$ & خط مبناى بايين & ماه & تيمار \\
\hline$\left(\mathrm{T}_{\mathrm{c}}-\mathrm{T}_{\mathrm{a}}\right)_{\mathrm{u} . \mathrm{l}}=6.41$ & $\mathrm{R}^{2}=85$ & $\left(\mathrm{~T}_{\mathrm{c}}-\mathrm{T}_{\mathrm{a}}\right)_{1.1}=3.73-0.16 \mathrm{VPD}$ & تير & \\
\hline$\left(\mathrm{T}_{\mathrm{c}}-\mathrm{T}_{\mathrm{a}}\right)_{\mathrm{u} . \mathrm{l}}=3.93$ & $\mathrm{R}^{2}=67$ & $\left(\mathrm{~T}_{\mathrm{c}}-\mathrm{T}_{\mathrm{a}}\right)_{1.1}=2.55-0.11 \mathrm{VPD}$ & 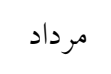 & TS \\
\hline$\left(\mathrm{T}_{\mathrm{c}}-\mathrm{T}_{\mathrm{a}}\right)_{\mathrm{u} . \mathrm{l}}=3.17$ & $\mathrm{R}^{2}=83$ & $\left(\mathrm{~T}_{\mathrm{c}}-\mathrm{T}_{\mathrm{a}}\right)_{l .1}=2.30-0.07 \mathrm{VPD}$ & شهريور & \\
\hline$\left(\mathrm{T}_{\mathrm{c}}-\mathrm{T}_{\mathrm{a}}\right)_{\mathrm{u} . \mathrm{l}}=5.82$ & $\mathrm{R}^{2}=83$ & $\left(\mathrm{~T}_{\mathrm{c}}-\mathrm{T}_{\mathrm{a}}\right)_{1.1}=3.51-0.17 \mathrm{VPD}$ & تير & \\
\hline$\left(\mathrm{T}_{\mathrm{c}}-\mathrm{T}_{\mathrm{a}}\right)_{\mathrm{u} . \mathrm{l}}=4.23$ & $\mathrm{R}^{2}=60$ & $\left(\mathrm{~T}_{\mathrm{c}}-\mathrm{T}_{\mathrm{a}}\right)_{1.1}=2.62-0.12 \mathrm{VPD}$ & 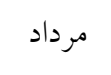 & $\mathrm{TK}$ \\
\hline$\left(\mathrm{T}_{\mathrm{c}}-\mathrm{T}_{\mathrm{a}}\right)_{\mathrm{u} . \mathrm{l}}=3.11$ & $\mathrm{R}^{2}=70$ & $\left(\mathrm{~T}_{\mathrm{c}}-\mathrm{T}_{\mathrm{a}}\right)_{1.1}=2.03-0.10 \mathrm{VPD}$ & شهريور & \\
\hline$\left(\mathrm{T}_{\mathrm{c}}-\mathrm{T}_{\mathrm{a}}\right)_{\mathrm{u} . \mathrm{l}}=6.56$ & $\mathrm{R}^{2}=84$ & $\left(\mathrm{~T}_{\mathrm{c}}-\mathrm{T}_{\mathrm{a}}\right)_{1.1}=4.02-0.17 \mathrm{VPD}$ & تير & \\
\hline$\left(\mathrm{T}_{\mathrm{c}}-\mathrm{T}_{\mathrm{a}}\right)_{\mathrm{u} . \mathrm{l}}=3.86$ & $\mathrm{R}^{2}=69$ & $\left(\mathrm{~T}_{\mathrm{c}}-\mathrm{T}_{\mathrm{a}}\right)_{1.1}=2.41-0.11 \mathrm{VPD}$ & 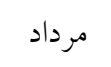 & TC \\
\hline$\left(\mathrm{T}_{\mathrm{c}}-\mathrm{T}_{\mathrm{a}}\right)_{\mathrm{u} . \mathrm{l}}=3.39$ & $\mathrm{R}^{2}=80$ & $\left(\mathrm{~T}_{\mathrm{c}}-\mathrm{T}_{\mathrm{a}}\right)_{1.1}=2.33-0.10 \mathrm{VPD}$ & شهريور & \\
\hline$\left(\mathrm{T}_{\mathrm{c}}-\mathrm{T}_{\mathrm{a}}\right)_{\mathrm{u} . \mathrm{l}}=6.35$ & $\mathrm{R}^{2}=93$ & $\left(T_{c}-T_{a}\right)_{l .1}=3.76-0.19 \mathrm{VPD}$ & تير & \\
\hline$\left(\mathrm{T}_{\mathrm{c}}-\mathrm{T}_{\mathrm{a}}\right)_{\mathrm{u} . \mathrm{l}}=4.04$ & $\mathrm{R}^{2}=78$ & $\left(\mathrm{~T}_{\mathrm{c}}-\mathrm{T}_{\mathrm{a}}\right)_{1.1}=3.10-0.16 \mathrm{VPD}$ & 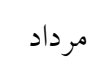 & FS \\
\hline$\left(\mathrm{T}_{\mathrm{c}}-\mathrm{T}_{\mathrm{a}}\right)_{\mathrm{u} . \mathrm{l}}=3.16$ & $\mathrm{R}^{2}=94$ & $\left(\mathrm{~T}_{\mathrm{c}}-\mathrm{T}_{\mathrm{a}}\right)_{1.1}=2.37-0.11 \mathrm{VPD}$ & شهريور & \\
\hline$\left(\mathrm{T}_{\mathrm{c}}-\mathrm{T}_{\mathrm{a}}\right)_{\mathrm{u} . \mathrm{l}}=6.32$ & $\mathrm{R}^{2}=95$ & $\left(\mathrm{~T}_{\mathrm{c}}-\mathrm{T}_{\mathrm{a}}\right)_{1.1}=3.60-0.19 \mathrm{VPD}$ & تير & \\
\hline$\left(\mathrm{T}_{\mathrm{c}}-\mathrm{T}_{\mathrm{a}}\right)_{\mathrm{u} . \mathrm{l}}=4.31$ & $\mathrm{R}^{2}=83$ & $\left(\mathrm{~T}_{\mathrm{c}}-\mathrm{T}_{\mathrm{a}}\right)_{\mathrm{l} .1}=3.15-0.16 \mathrm{VPD}$ & 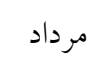 & FK \\
\hline$\left(\mathrm{T}_{\mathrm{c}}-\mathrm{T}_{\mathrm{a}}\right)_{\mathrm{u} . \mathrm{l}}=3.14$ & $\mathrm{R}^{2}=91$ & $\left(\mathrm{~T}_{\mathrm{c}}-\mathrm{T}_{\mathrm{a}}\right)_{1.1}=2.36-0.11 \mathrm{VPD}$ & شهريور & \\
\hline$\left(\mathrm{T}_{\mathrm{c}}-\mathrm{T}_{\mathrm{a}}\right)_{\mathrm{u} .1}=6.56$ & $\mathrm{R}^{2}=93$ & $\left(\mathrm{~T}_{\mathrm{c}}-\mathrm{T}_{\mathrm{a}}\right)_{1.1}=4.11-0.19 \mathrm{VPD}$ & تير & \\
\hline$\left(\mathrm{T}_{\mathrm{c}}-\mathrm{T}_{\mathrm{a}}\right)_{\mathrm{u} . \mathrm{l}}=3.86$ & $\mathrm{R}^{2}=83$ & $\left(\mathrm{~T}_{\mathrm{c}}-\mathrm{T}_{\mathrm{a}}\right)_{1.1}=3.09-0.16 \mathrm{VPD}$ & 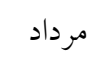 & FC \\
\hline$\left(\mathrm{T}_{\mathrm{c}}-\mathrm{T}_{\mathrm{a}}\right)_{\mathrm{u} . \mathrm{l}}=3.27$ & $\mathrm{R}^{2}=95$ & $\left(\mathrm{~T}_{\mathrm{c}}-\mathrm{T}_{\mathrm{a}}\right)_{1.1}=2.46-0.11 \mathrm{VPD}$ & شهريور & \\
\hline
\end{tabular}

قبل آبيارى و خطوط مبناى بالا و وِايين تعيين شده براى مـاه

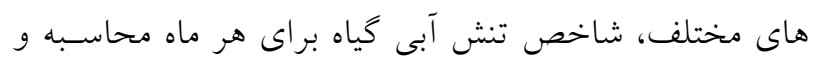

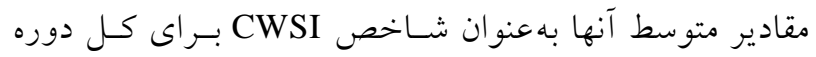

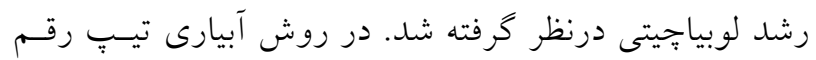
كوشا با متوسط 11/ و و روش سطحى رقـم كوشـا و COS 16با مقدار سٓ/ه كمترين مقدار شاخص تنش آبى را در طول فصل دارند. درحالى كه بيشـترين مقــار شـاخص در هـر دو

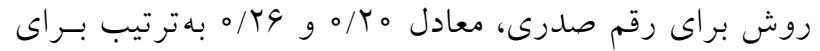
روش تيبٍ و سطحى حاصـل شـــ مقايسـه ميـانخين مقــادير

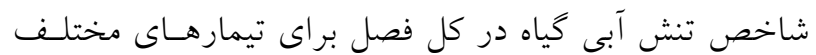

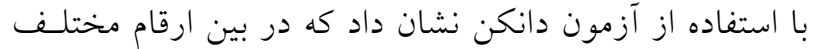

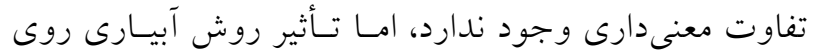
آن معنى دار است (شكل V). عامل مؤثر در تفاوت ايجاد شده
نيز بيان كرد شيب و عرض از مبدأ در معادله خط مبنـاى بـايين

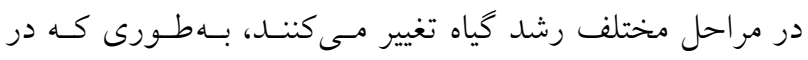

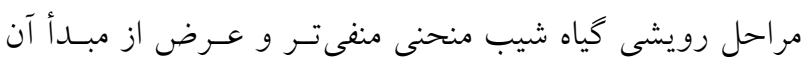
مثبت تر از مراحل زايشى است. در اين تحقيق نيز همانطور كـهـ مشاهده مىشود بهعنوان مثال براى رقم صدرى در روش تيـِّ، مقدار شيب خطوط مبنا در مراحل اوليسه و رويشسى رشـد كيـاه

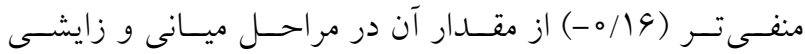
(- است. همجنين مقادير عرض از مبدأ در مراحل اوليسه

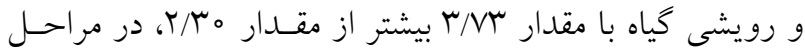
ميانى و زايشى رشد است.

CWSI Cماسبه شاخص بر اساس اندازهخيرىهاى مزرعهاى انجـام شـــه در روزهـاى 


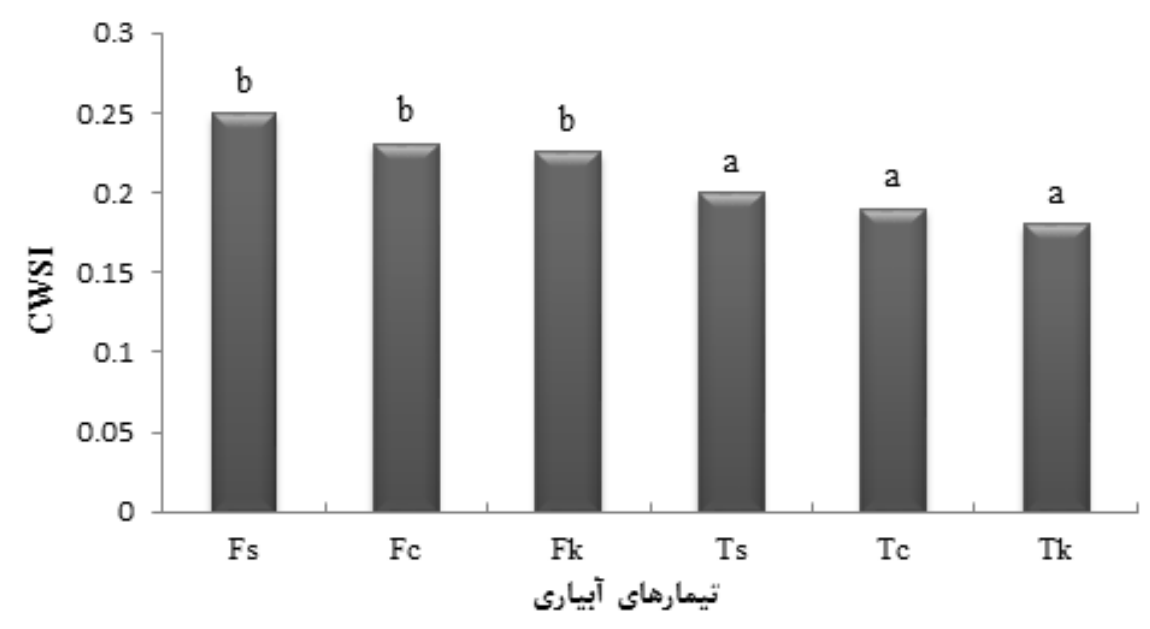

شكل V. مقايسه ميانگين مقادير CWSI در طول فصل رشد در تيمارهاى مختلف آيارى

تعيين زمان آبيارى با استفاده از شاخص CWSI

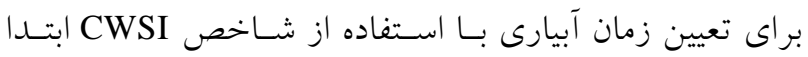

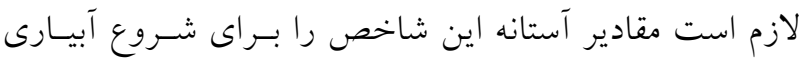

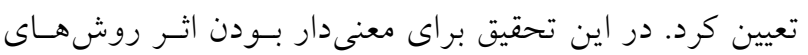

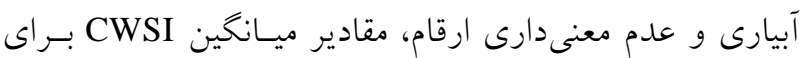

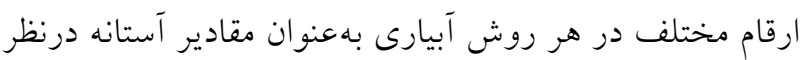

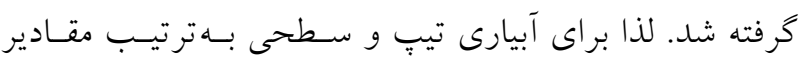

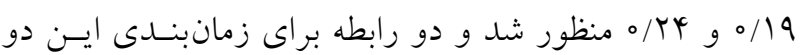
روش در جدول V ارائه شد. براى استفاده از اين روابط بـراى

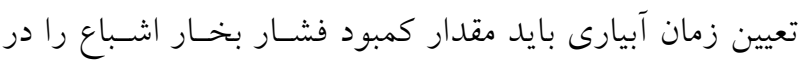

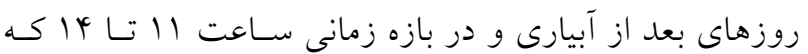
كياه با حداكثر تنش روزانه مواجه است اندازهيرى كـرد و بـا جايخذارى در معادله ارائه شده در جدول، اختلاف مجاز براى دماى برى و هوا را محاسبه كرد. از طرف ديخر اختلاف دماى

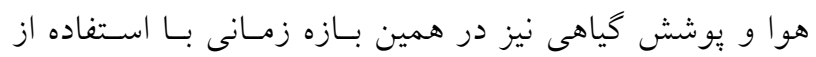

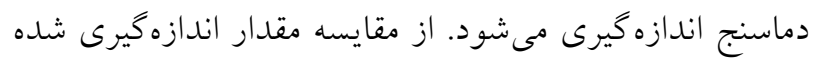
و مقدار مجاز محاسبه شده مىتوان زمان آبيارى را تعيين كرده،

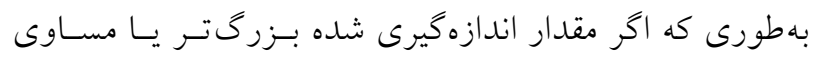

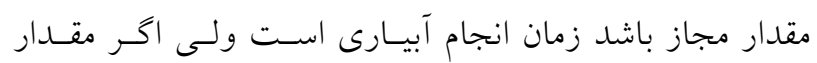

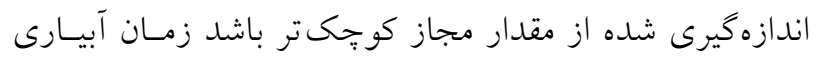

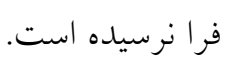

در مقادير شاخص تنش آبسى كيـاه، اخستلاف دمـاى بوشـش سبز و هوا است. شـاخص تسنش CWSI بـا تغييـرات تبخيـر و تعرق همبستخى منفى و بالايى دارد، بـه ايسن صسورت كـهـ

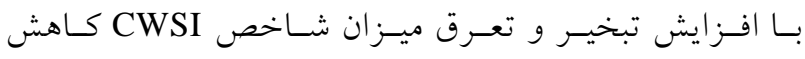

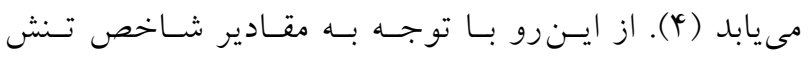

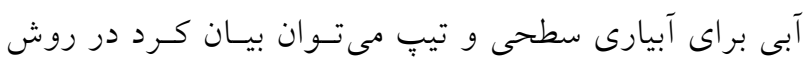

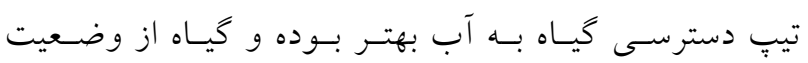
رطوبتى مطلوبترى نسبت به روش سطحى برخهـوردار بـوده بهمنظور بررسى روند تغييرات شـاخص CWSI در طسول

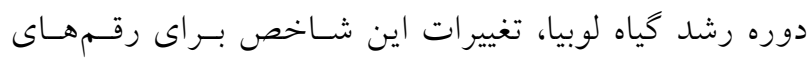
مختلف در روش تيٍ و سطحى بهترتيب در شكلهــاى ^و

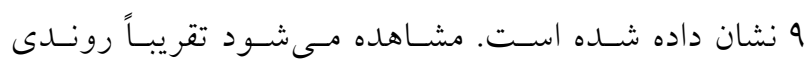
يكسان در رقمهاى مختلف وجود دارد. تغييرات اين شاخص در طول دوره رشد نشان از تغيير وضـيت رطـوبتى كيـاه در مراحل مختلف رشد است. با توجه به اين شكل ها، در مرحله

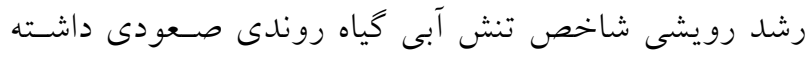

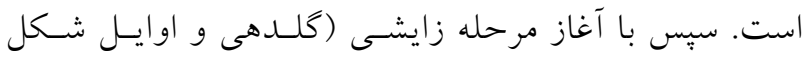

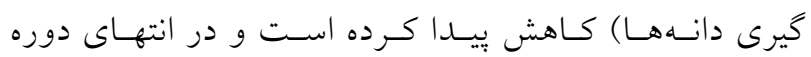

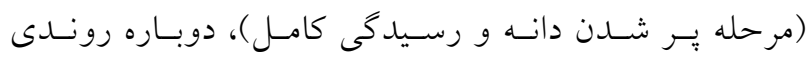
افزايشى بهخود كرفته است. 


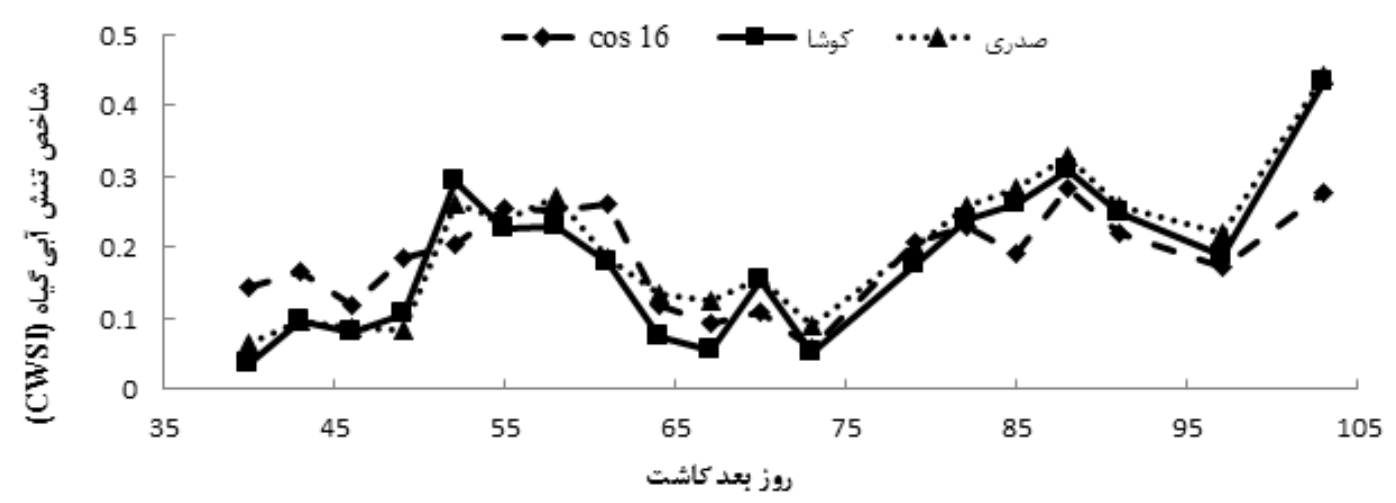

شكل ^. تغييرات شاخص CWSI در طول فصل رشد تيمارهاى مختلف آبيارى تيب

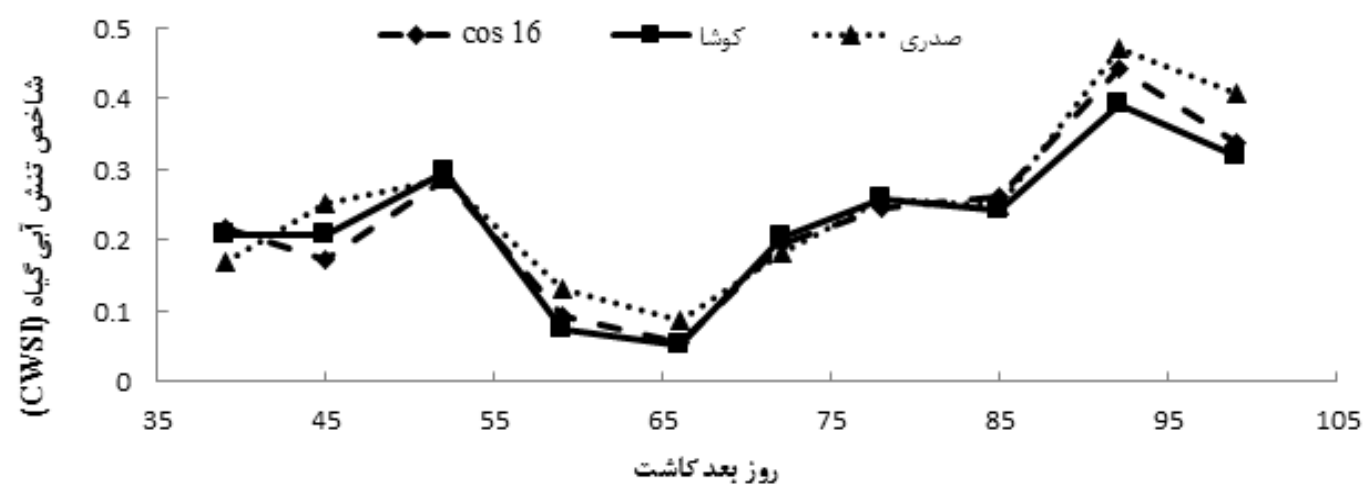

شكل 9. تغييرات شاخص CWSI در طول دوره رشد تيمارهاى مختلف آبيارى سطحى

جدول V. روابط برنامهريزى آبيارى ذرت تحت روشهاى آبيارى سطحى و تيب

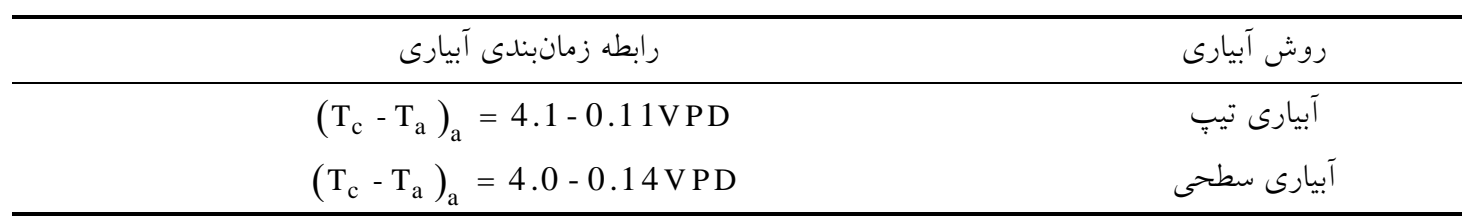

نيست. بر اين اساس متوسط مقادير شاخص تنش آبى گياه در تنيجحه كيرى رقمهاى مختلف از هر روش محاسبه و بهعنوان مبنـايى بـراى در اين تحقيق، ابتدا روابط خطوط مبناى بالا و يايين براى هـر تعيين زمان آبيارى درنظر كرفته شد. مقدار شاخص تنش آبى ماه در سه رقــم لوبيـاجِيتى شـامل COS16، صـدرى و كوشـا كياه براى آبيارى تيبٍ و سطحى بهترتيب مقادير 19/ه و و تحت دو روش آبيارى سطحى و تيب تعيين شـد و سـس بـ بـا

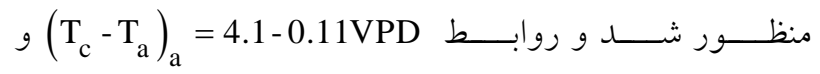
استفاده از اين روابط متوسط شاخص تنش آبى كيـاه در طـول بـــــ (T فصل محاسبه شد. نتايج اين مطالعه نشان داد تأثير روشهـاى استخراج شد. آبيارى روى مقادير شاخص تنش آبى كياه در سطح ه درصـد

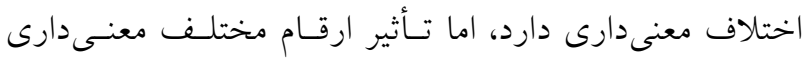


1. Agricultural Statistics 2015-16. 2017. Ministry of Jahad-e-Keshavarzi, Deputy Director of Planning and Economics, Center for Information and Communication Technology. (In Farsi).

2. Ahmadi, H., A. H. Nasrollahi, M. Sharifipur and H. R. Isvand. 2018. Determination of soybean water stress index (CWSI) for irrigation management for maximum yield and water productivity. Iranian Journal of Irrigation and Water Engineering 8(32): 47-56. (In Farsi).

3. Asemanrafat, M. and T. Honar. 2017. Effect of water stress and plant density on canopy temperature, yield components and protein concentration of red bean (Phaseolus vulgaris L. cV. Akhtar). International Journal of Plant Production 11(2): 241-258.

4. Ben-Gal, A., E. Ityel, L. Dudley, S. Cohen, U. Yermiyahu, E. Presnov and U. Zigmond Land Shani. 2008. Effect of irrigation water salinity on transpiration and leaching requirements: A Case study for bell peppers. Agricultural Water Management 95: 587-597.

5. Boroumand Nasab, S., S. Taheri Ghannad and M. Moayeri. 2004. Application of Green Plant Cover Temperature for Irrigation Planning of Spring Corn in Khuzestan Conditions. Scientific Journal of Agriculture 27: 56-47. (In Farsi)

6. Colak, Y. B, A. Yazar, I. Colak, H. Akca and G. Duraktenkin. 2015. Evaluation of crop water stress index (CWSI) for eggplant under varying irrigation regimes using surface and subsurface drip systems. Agriculture and Agricultural Science Procedia 4: 372 - 382.

7. DeJonge, K. C., S. Taghvaeian, T. J. Trout and L. H. Comas. 2015. Comparison of canopy temperature-based water stress indices for maize. Agricultural Water Management 156: 51-62

8. Durigon, A. and Q. D. J. van Lier. 2013. Canopy temperature versus soil water pressure head for the prediction of crop water stress. Agricultural Water Management 127: 1- 6.

9. Feyizi Asl, V., A. Fotovat, A. Asteraky, A. Lakzian and A. Mousavi Shlamani. 2014. Determination of water balance and its critical stages in rainfed wheat using water stress index (CWSI). Water and Soil Journal (Agricultural Sciences and Technology) 28(4): 817-804. (In Farsi).

10. Fattahi Dolatabadi, Kh., H. Babazadeh, P. Najafi and H. Sedghi. 2018. A Model for Irrigation Planning Using Difference Between Air Temperature and Corn Leaf Area. Journal of Water Research in Agriculture 2(32): 321305. (In Farsi).

11. Gerhards, M., G. Rock, M. Schler and T. Udelhoven. 2016. Water stress detection in potato plants using leaf temperature, emissivity, and reflectance. International Journal of Applied Earth Observation and Geoinformation 53: 27-39.

12. Ghorbani, M. and S. Boroumand Nasab. 2016. The effect of salinity of water in surface irrigation on plant water stress index (CWSI) in plantation of summer corn irrigation. Journal of Irrigation and Water Engineering 7(25): 6754. (In Farsi).

13. Habibpourkashefi, A., M. H. Qarineh, A. R. Shafeiynia and M. Roozrokh. 2015. Effects of zeolite levels on chlorophyll fluorescence of red beans (Phaseolus vulgaris L.) under drought conditions. Quarterly Journal of Plant Growth Physiology 7(28): 32-1. (In Farsi).

14. Idso, S. B. 1982. Non-water-stressed baselines: a key to measuring and interpreting plant water stress. Agricultural Meteorology 27(1-2): 59-70.

15. Idso, S. B., R. D. Jackson and R. J. Reginato. 1977. Remote sensing of crop yields. Science 196: 19-25

16. Idso. S. B., R. D. Jackson, P. J. Pinter, R. J. Reginato and J. L. Hatfield. 1981. Normalizing the stress-degree-day parameter for environmental variability. Journal of Agricultural Meteorology 24: 45-55.

17. Khorsandi, A., A. Hemmat, S. A. Mireei, R. Amirfattahi and P. Ehsanzadeh. 2018. Plant temperature-based indices using infrared thermography for detecting water status in sesame under greenhouse conditions. Agricultural Water Management 204: 222-233.

18. Machado, N. N. B. and M. A. B. Duraes. 2006. Physiological and biochemical response of common bean varieties treated with salicylic acid under water stress. Crop Breeding and Applied Biotechnology 6: 269-277.

19. Mart'inez, J. P., H. Silva, J. F. Ledent and M. Pinto. 2007. Effect of drought stress on the osmotic adjustment, cell wall elasticity and cell volume of six cultivars of common beans (Phaseolus vulgaris L.). European Journal of Agronomy 26: 30-38.

20. Nourbakhsh, S. S., M. Ghobadiniya, A. Shahraki, M. Imamzadehi and R. Nafchi. 2015. Effect of time and irrigation water on water use efficiency and bean yield in dry and semi-dry conditions. Journal of Soil and Water (Agricultural Sciences and Technology) 29(1): 47-35. (In Farsi).

21. Osroosh, Y., R. T. Peters, C. S. Campbell and Q. Zhang. 2015. Automatic irrigation scheduling of apple trees using theoretical crop water stress index with an innovative dynamic threshold. Computers and Electronics in Agriculture 118: 193-203. 
22. Saeedinia, M., S. Boroumand Nasab, A. Hooshmand, A. Soltani Mohammadi and B. Andarzian. 2016. The applicability of CWSI index for planning of corn irrigation with saline water in Ahvaz. Water and Soil Knowledge 26(1): 185-173. (In Farsi)

23. Seifi, A., S. M. Mir Latifi, H. Dehghani Sanij and M. Torabi. 2014. Determination of water stress index for pistachio trees under subtropical drip irrigation using temperature difference between plant and air corona. Journal of Water and Irrigation Management 4(1): 136-123. (In Farsi).

24. Sezen, S. M., A. Yazar and S. Tekin. 2019. Physiological response of red pepper to different irrigation regimes under drip irrigation in the Mediterranean region of Turkey. Scientia Horticulturae 245: 280-288.

25. Sezen, M. S., A. Yazar, Y. Dasgan, S. Yucel, A. Akyıldız, S. Tekin and Y. Akhoundnejad. 2016. Evaluation of crop water stress index (CWSI) for red pepper with dripand furrow irrigation under varying irrigation regimes. Agricultural Water Management 143: 59-70.

26. Torres, C. A., A. Sepúlveda, L. Leon and J. A. Yuri. 2016. Early detection of sun injury on apples (Malus domestica Borkh.) through the use of crop water stress index and chlorophyll fluorescence. Scientia Horticulturae 211: 336342.

27. Walker, G. K. 1980. Relation between crop temperature and the growth and yield of kidney beans (Phaseolus vulgaris L.), Ph.D Thesis, Univermty of Cahfornia, Davis, CA.

28. Weysi, Sh., A. Naseri and S. Hamza. 2016. Determination of irrigation time of sugarcane farms using thermal infrared thermometer and soil moisture of root zone. Water and Soil Conservation Research 23(6): 251-235. (In Farsi).

29. Weysi, S., A. Naseri, S. Hamzeh and H. Bartholomeus. 2017. A satellite based crop water stress index for irrigation scheduling in sugarcane fields. Agricultural Water Management 189: 70-86.

30. Zia, S., G. Romano, W. Spreer, C. Sanchez, J. Cairns, J. L. Araus and J. Muller. 2013. Infrared thermal imaging as a rapid tool for identifying water stress tolerant maize genotypes of different phenology. Agronomy and Crop Science 75-84. 


\title{
Comparison of Variations of Water Stress Index of Chika Bean Plant under Surface Irrigation and Drip Tape Irrigation using Infrared Thermometer
}

\author{
A. H. Nasrollahi ${ }^{*}$, H. Ahmadi, Y. Sabzevari and S. Nouri ${ }^{1}$
}

(Received: May 30-2019 ; Accepted: August 3-2019)

\begin{abstract}
The Plant Water Resistance Index (CWSI) is a tool that can be used for the rapid monitoring of plant water status, which is a key requirement for the accurate product irrigation management.The purpose of this study was to calculate the CWSI index for bean hares in the Khorramabad region for two methods of surface irrigation and drip tape irrigation. For this purpose, a design was implemented in the form of randomized complete block design and split plot experiment. The main factors included drip tape irrigation $(\mathrm{T})$ and surface irrigation $(\mathrm{F})$, and the cultivars of Chibi cultivars including COS16 (C), Sadri (S) and diluted (K) served as sub-plots. By using the field measurements, the position of the upper and lower base lines was estimated for each treatment in different months and used to calculate the CWSI index. The results showed that CWSI values calculated in the surface irrigation during plant growth period were always higher than those in the drip tape irrigation. The highest value of CWSI index was obtained for the Sadri variety, which was equal to 0.20 and 0.26 , for the type and surface method, respectively. Statistical analysis showed that the effect of irrigation method on the amount of water stress index was significant at $5 \%$ level, but there was no significant difference between different cultivars. According to the results of this study, the threshold values for CWSI were considered to be 0.19 and 0.24 for surface and drip tape irrigation respectively, and relationships were presented based on the differences in vegetation and air temperature to determine the irrigation time.
\end{abstract}

Keywords: Irrigation planning, Water stress, Leaf temperature.

1- Department of Water Engineering, Faculty of Agriculture and Natural Resources, Lorestan University, Khorramabad, Iran.

*: Corresponding author, Email: nasrolahi.a@lu.ac.ir 